\title{
Students Conception of Voltage and Resistance Concepts after Conventional Instruction
}

\author{
Fikadu Eshetu ${ }^{1 *}$, Mekbib Alemu ${ }^{2}$ \\ ${ }^{1}$ PhD Candidate, Department of Science and Mathematics Education, Addis Ababa University, Addis Ababa, ETHIOPIA \\ ${ }^{2}$ Assistant Professor, Department of Science and Mathematics Education, Addis Ababa University, Addis Ababa, ETHIOPIA
}

Received 23 January 2018 - Revised 24 April 2018 - Accepted 26 April 2018

\begin{abstract}
The purpose of this study was to determine the level of conceptions reached by students' who learnt the concepts of voltage and resistance with the conventional direct instruction. To answer the research questions, descriptive non-experimental research design was used. A two tier test on the concepts of voltage and resistance was administered to 49 physics and chemistry major first year students in Medda Walabu University, Ethiopia. Students' responses to the five items were qualitatively compared to those found in literature for secondary school and university students. The result showed that the conception of students formed at school level about voltage and resistance were not that much affected even by learning the same concepts at advanced levels and with mathematical rigor at university. Besides, the analysis revealed that students hold multiple opposing ideas regarding the same concept, which contradicts the classical conceptual change perspective. Further, the average conception level reached by the students after learning university level physics courses was "partial understanding". Therefore, attending advanced but traditional course would not enhance students' conceptual understanding. Hence, teachers should have to investigate students' conceptions, as a first step, to subsequently design and implement appropriate instructional interventions.
\end{abstract}

Keywords: students' conceptions, two-tiered test, voltage and resistance concepts

\section{INTRODUCTION}

The plethora of research in students' conception and conceptual change evidenced the fact that many students were found to be clinging to their conceptions other than that of scientists. This negatively affects students' ability in solving real life problems in school curriculum (Tsai, 2003) as well as in their future science/physics related career (Li \& Singh, 2016). Lack of success in learning physics in general and theoretical concepts such as force, acceleration, and voltage, is strongly contributing to the low acceptance rate by students and the broader view of physics as difficult subject (Taconis \& Kessels, 2009).

Learning is a complex process whereby learners' construct knowledge for themselves from their personal experience and social interactions. Learning concrete as well as theoretical concepts of physics is complicated by the fact that the prior knowledge that students build from their experience usually do not overlap with the scientifically accepted knowledge (Duit \& Treagust, 2003). Even though, these students' ideas of a scientific phenomenon were referred to by different terminologies (Treagust \& Duit, 2009), they are most commonly called misconceptions. Misconception is defined as the assumption and inaccurate description of particular phenomenon that is created by an individual based on his/her experiences (Martin, Sexton, \& Gerlovich, 2002). This occurs in the teaching and learning process as a result of conflict between the knowledge built based on experience and the scientific idea that is introduced in school. In addition to students' personal experience with the physical reality, their social interactions mediated by school textbooks, language used and teachers are all considered as important sources of misconceptions (Kaltakçı \& Eryilmaz, 2010). These misconceptions prevent students from the true path

(C) 2018 by the authors; licensee Modestum Ltd., UK. This article is an open access article distributed under the terms and conditions of the Creative Commons Attribution License (http://creativecommons.org/licenses/by/4.0/). $\square$ fik4jju@gmail.com (*Correspondence) $\square$ mekbibalemu@yahoo.com 


\section{Contribution of this paper to the literature}

- The study showed that the conceptions formed by the students at school level about voltage and resistance were not changed even after learning advanced course.

- It finds out that the high-level physics course taught using the traditional instruction results in an unsatisfactory students' conceptual understanding.

- The study revealed that, students can hold multiple opposing ideas about the same concept instead of 'revolutionarily' replacing one by the other as suggested by the classical conceptual change perspective.

of knowledge and lead one towards misunderstanding and thus unable to achieve the current and future learning objectives.

Children's conceptions, and secondary school and university students' misconceptions in different areas of physics had been studied so far (Bilal \& Erol, 2009; Chee, 2010; Dilber, Karaman, \& Duzgun, 2009; Li \& Singh, 2016; Tanel \& Erol, 2008). Studies about students' conceptions of electricity and magnetism concepts at secondary schools and universities were also available (Engelhardt \& Beichner, 2004; Kock, Taconis, Bolhuis, \& Gravemeijer, 2013; Li \& Singh, 2016). In their diagnostic instrument development work, Engelhardt and Beichner (2004) identified a longer list of students' difficulties (including students' misconceptions) in relation to direct current resistive circuit. In their study, secondary school students and university students were also compared with slightly better performance of university students. The work of Kock et al. (2013) summarized specific misconceptions held by secondary school students obtained from many studies over decades. The secondary school students' misconceptions identified in the summaries of Engelhardt and Beichner (2004) and Kock et al. (2013) include: (a) confusion in important concepts such as current and voltage, and attribution of resistance to current, (b) use of the idea that current is consumed in a circuit (or use of unipolar, clashing or shared current models), (c) viewing power supplies as a source of constant current instead of constant potential difference, (d) considering power supply as a source of charge; so thinking that only those bulbs with a direct contact to the power supply will light (e) failing to realize that a change of one element can have an impact on the current in the whole circuit, and (f) considering electric circuit as a sequential system in which only changes before an element will affect that element's behavior, not other elements in the circuit.

In the scares of research in Ethiopia, students were also found to share the same problems as students elsewhere. For instance, the study conducted by Getinet (2007) on Newtonian Mechanics showed that misconceptions are common among university students. Unfortunately, local literature did not cover all areas of physics and students' conceptions. Therefore, Ethiopian students' ideas in most cases including in electricity and magnetism are not known. National examination scores and National Learning assessment results however indicated that there is a serious problem in physics in primary and secondary schools of Ethiopia (Federal Ministry of Education, 2015; Semela, 2010; Shibeshi, Mekonnen, Semela, \& Endawoke, 2009). The common characteristic of physics teachers in teaching undergraduate physics is transmitting the logical structures of their knowledge through lecture (Bekalo \& Welford, 1999; Getinet, 2012; Mekonnen, 2014). The teaching methods predominantly used by lecturers in physics classrooms and in general in teaching science forced students to become passive recipients and compromised acquisition of process and inquiry skills (Bekalo \& Welford, 1999; Esayas, 1995; Treagust \& Duit, 2009). According to Getinet (2007), the use of lecture method so as to provide students with bunches of facts, principles, laws, and derivation of mathematical expressions has little benefit to students' conceptual understanding.

Traditional physics instruction has been commonly reported to be ineffective in achieving major goals of physics instruction. That is, influences of the traditional physics instruction on students' understanding of physics concepts, problem-solving skills, and motivation in physics have not been found to be satisfactory by the Physics Education Research community (Taasoobshirazi \& Carr, 2008). The research done by Getinet, in conformity with other researchers (Semela, 2010; Shibeshi et al., 2009), also attributed the high level of misconceptions and very low achievement problems to the traditional lecture based teaching method frequently used by physics teachers in schools and universities. These issues have forced researchers to develop alternative teaching methods. There is an extensive literature about the effectiveness of alternative methods. For example, Hake (1998) compared the effect of traditional and interactive-engagement methods on students' conceptual understanding of physics. As a result, the interactive-engagement methods were observed to be significantly better in promoting students' conceptual understanding. Baser and Geban (2007) also demonstrated the effectiveness of conceptual change oriented instruction in grade 10 physics instruction in Turkey.

As many conceptual change theoreticians indicated, Ozdemir and Clark (2007) also contended that instruction and research should not be guided by a single perspective. From one perspective, instructional design for conceptual change should consider the nature of students' knowledge as theory like, that means as a coherent unified framework that may change when the student is dissatisfied with it and a good and powerful replacement is found. The other perspective demands that knowledge to be viewed as ecology which is assortment of quasi- 
independent elements and therefore, which changes gradually allowing for coexistence of contradictory conceptions at the same time. It is also the recommendation of Treagust and Duit (2009) to take into account the multiplicity of nature in conceptual change domain and therefore either individual perspectives as well as multiple perspectives should be employed.

In Ethiopia, although the government encourages instructors to use active learning strategies, teachers are observed sticking to what they call talk-and-chalk teaching while ignoring the implementation of student-centered instruction (Adula \& Kasahun, 2010; Mekonnen, 2014). As a result, the teaching methods commonly used by the instructors in higher education institutions is more of lecturing sometimes supported by group discussions and the like. Hence, the instructors' tendency to implement other conceptual change strategies was not reported in literature. But regardless of the type of teaching method used, the teachers' role is crucial in tackling misconceptions of students since students possess misconceptions at any level.

On the other hand, many of the sources of confusion in science classes are not identified in the classroom as instruction occurs. A research conducted in a recent year has also indicated a wide range of misconceptions in physics which students have apparently formed even after receiving formal instruction (Dalaklioğlu, Demirci, \& Şekercioğlu, 2015). It is, therefore, important to investigate students' alternative conceptions concerning specific scientific concepts, as a first step, so that subsequently appropriate instructional interventions can be made. Of course, it is believed that classroom environment which encourages active learning of students (like dialogic teaching in which students are given physical phenomena to discuss and suggest their own explanations and support and rebut claims with evidence) potentially enables teachers in monitoring students' understanding.

According to Osborne (1985), Ross, Lakin, and Callaghan (2000), and Staver (2007), it is crucial in science teaching to identify misconceptions or alternative conceptions of students. Investigating children's ideas is important for both students and teachers (Duit, Treagust, \& Mansifield, 1996; Ross et al., 2000). It helps teachers to understand existing levels of students and allows the students to compare existing ideas with new ones. In addition to these, documenting all the alternative conceptions held by students could contribute to lecturers' ability to effect conceptual change as well as benefit and inform science curriculum planning (Driver, 1989). Otherwise, the students would become alien to them being unable to assimilate new knowledge into their existing level. Therefore, teachers need to know ideas of scientists about the concepts to be taught as well as the misconceptions of students in order to promote effective science teaching. The fact that students' conceptions are amenable to instructional strategies were presented by such theoretical works as in Treagust and Duit (2009) and demonstrated very well in the research report by Kock, Taconis, Bolhuis, and Gravemeijer (2015).

Besides the teaching method, in Ethiopia, teachers in general and physics teachers in particular are from low academic status (Semela, 2010; Singh, 2014). Students placed to physics department who are mainly to become secondary school teachers, are those who failed to join other fields of study due to their low scores in university entrance examination. They were placed to study physics without their interest and choice (Getnet, 2007; Semela, 2010). Getinet's study revealed that students placed to physics department had poor ability in school mathematics. Consequently, they were unable to understand the concepts of physics. As a result, their performance in exam was found to be very poor and hence subjected to delay and/or dismissal in their university study. Other studies also report similar results indicating the persistent and deep-rooted problems in the quality of students learning of physics at pre-university level (Shibeshie et al., 2009; Semela, 2010).

In order to identify and measure students' concept understanding, different diagnostic tools have been developed and used. Among them, the two-tier test has been widely used to identify student misconceptions on science concepts (Gurel, Eryılmaz, \& McDermott, 2015; Treagust \& Haslam, 1986; Wang, 2004). Two-tier tests were considered a great improvement over the previous approaches in that these tests consider students' reasoning or interpretation behind their selected response and link their choices to misconceptions of the target concept (Wang, 2004). Since Treagust (1986) published his seminal work on the development of two-tier test, large number of researchers have developed and administered two-tier diagnostic tests in science subjects (Gurel, et al., 2015). But, in Ethiopia, the usual type of assessment used in classrooms is achievement test. Besides this, although instructors are encouraged to use active learning methodologies, their effort to identify students' alternative conceptions is weak or alternatively not reported in the literature. This study identified and documented first year physics and chemistry degree students' conception of voltage and resistance concepts previously covered in the secondary schools with the use of a two-tier test in Medda Walabu University, Ethiopia. Arising from the issues mentioned above, the following research questions were addressed in this study.

1. What are the levels of conceptions of first year university students about voltage and resistance concepts after taking electricity and magnetism course?

2. Are there differences in conception levels of the students due to some background factors after taking the same course in electricity and magnetism? 
3. Are there evidences to conclude that the high-level university physics course improves students' conceptions levels regarding concepts of voltage and resistance?

\section{RESEARCH METHODOLOGY}

To obtain relevant information regarding university students' conceptions of voltage and resistance after they studied the topics through conventional direct instruction where the dominant pedagogy was lecturing, descriptive non-experimental research design was used. This is because the study was conducted with an aim to describe a phenomenon or document its characteristics. To identify students' conceptions of voltage and resistance concepts, two-tiered test was administered to first year physics and chemistry major students at the end of the instruction. The test consisted of 5 two-tier questions with two of the items probing students' conception of voltage and the other three (item 3,4, and 5) probing the concepts of resistance. Four of the items were selected and partially modified from studies investigating students' ideas about simple electric circuits in the literature. Two of the items were selected from Vatansever (2006) and the rest two from Urban-Woldron (2013). The remaining item was prepared by the researchers taking into account the misconceptions found in literature. These items were based on the basic concepts of voltage and resistance that were covered in the secondary school curriculum. In the two-tier diagnostic instrument, the first tier of each item in the test was a multiple-choice question having three to five distracters along with the correct answer and the second tier was composed of a multiple-choice set of reasons for the answer to the first tier. The reasons provided for students contain the correct reason (answer) and possible distracters based on known student misconceptions. The test was administered as a regular test which was part of the continuous assessment of students in the two courses a week after the end of the unit dealing with the topics under investigation were completed. On the other hand, validity was assured by panels of experts comprising university lecturers and researchers familiar with conceptual change researchers. Furthermore, the test was piloted and its reliability coefficient was determined. The coefficient of reliability obtained was 0.73 which is at the acceptable level of reliability in such measurements.

First year physics major and chemistry major students' who have taken the course 'Electromagnetism' and 'Electricity and Magnetism', respectively, at Medda Walabu University as it is demanded by the harmonized university curriculum in Ethiopia (Woldeghebriel \& Tenaw, 2013) participated in the study. The total number of students from the physics majors was 17 while those from chemistry department were 32. As a result, all first-year physics and chemistry department students (a total of 49) in Medda Walabu University participated in the study. The participant groups were considered to have almost similar background in the physics learning, particularly in electricity topics as they learned from the same physics curriculum in the high school and no electricity related course were given in the previous university semester. Furthermore, the two courses were more or less similar and are offered based on such text books as Serway and Jewett (2008), and Walker, Resnick, and Halliday (2014). Besides the general introductory approaches in the course for chemistry majors, the only difference observed between the two courses were the dropping of few advanced level physics topics for chemistry majors, which were presumed to be irrelevant for chemistry learning. Hence, the content covered in relation to voltage and resistance in particular was found to be basically identical. The only significant background difference between the two groups is in their entry characteristics. In literature, students who joined the physics department are those with a weaker entry background when compared with others (Semela, 2010; Shibeshi et al., 2009). As depicted in the document obtained from the University, the physics students in this study were assumed to be with somehow inferior motivational levels to join the department than those who joined the chemistry department.

In the data analysis, statistical and qualitative judgments were employed item by item to the first and second tiers separately. So as to see whether most of the students' responses were far from guessing, Chi-square $\left(\chi^{2}\right)$ test was conducted. In order to analyze students' level of conceptual understanding, correct response rates were determined and the two groups of students were compared in terms of their highest mean percent correct responses. Percentage distributions among the alternatives given against each item in the first and second-tier were used to determine the predominant conceptions of students. These conceptions were qualitatively compared with results obtained in literature. Finally, in order to determine students level of conceptions, the most familiar method of categorizing with two-tier items that was introduced by Tarakçı, Hatipoğlu, Tekkaya, and Özden (1999) and which was used in similar area of research (Cocstu \& Ayas, 2005; Ozkan \& Selcuk, 2015) was used. With the rating skim, total conception levels of the two groups of students were determined and statistically compared. Throughout the analysis, a p-value of less than 0.05 was considered to be statistically significant.

\section{RESULTS}

Before classifying student's responses into the various conceptions levels, checking for randomness was conducted for the first and second tiers separately. Students responses showed clearer preference to most of the first-tier items except item $5(\chi 2=8.449, \mathrm{p}=0.076)$ in which they were required to answer conceptual question with a 
Table 1. Percentage of correct responses for the first-tier items for all students

\begin{tabular}{ccccc}
\hline & Total $(\mathbf{N})$ & Total (\%) & $\chi^{\mathbf{2}}$ & P-Value \\
\hline Item 1 & 42 & 85.71 & 25.00 & 0.000 \\
\hline Item 2 & 9 & 18.37 & 9.375 & 0.000 \\
\hline Item 3 & 22 & 44.90 & 0.326 & 0.475 \\
\hline Item 4 & 27 & 55.10 & 0.735 & 0.475 \\
\hline Item 5 & 15 & 30.61 & 7.375 \\
\hline
\end{tabular}

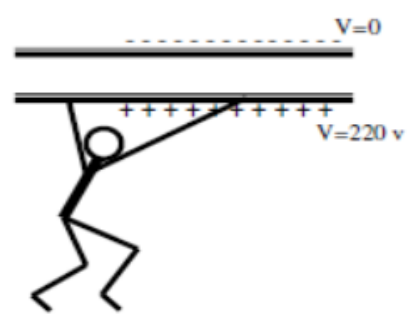

Fig. 1

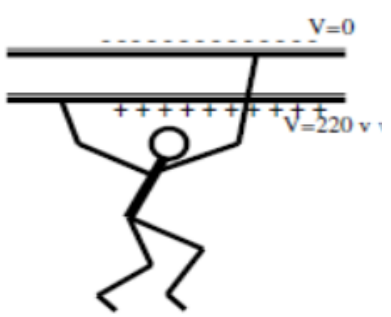

Fig.2

Figure 1. The two figures in item 2 showing two boys hanging from charged parallel plates. Adapted from "Effectiveness of Conceptual Change Instruction on Overcoming Students' Misconceptions of Electric Field, Electric Potential and Electric Potential Energy at Tenth Grade Level," by Vatansever, 2006, p. 95.

circuit having a resistor placed in between two light bulbs. This slight randomness did not render this item worthless as students' responses were confirming what Li and Singh (2016) found for introductory physics students in Turkey. Thus, in general it can be said that all the five items in the first-tier were functioning well in revealing the first-year physics and chemistry students' conceptions about voltage and resistance.

The percentage of correct responses to the first-tier items for the whole first-year students who took the 'Electromagnetism' and 'Electricity and Magnetism' courses at Medda Walabu University is presented in Table 1. The analysis presented in Table 1 was conducted through dichotomous coding of students' responses to the firsttier items, i.e., as correct and incorrect responses.

Both the highest and lowest correct response rates were obtained in relation to the first and the second items. The two items were targeted on students' conceptions about voltage. Even though the items basically involve similar realistic situations about high voltages, their successes in responding to these items were dramatically different. Item 1 was about a bird resting on a high voltage transmission cable while the second one was about boys hanging from high voltage difference conducting plates. In the first item, students were asked about the safety of a bird resting on a high voltage transmission cable. Practically, this is a common observation to students in Ethiopia as it is a country of a large family of birds. Every morning throughout the year birds are seen resting on electric transmission cables wherever one goes. As a result, many of the students $(85.71 \%, \chi 2=25.000, p=0.001)$ got the first item correct.

Unlike the content of the first item, item 2 was about unfamiliar and idealistic condition. In this item, two boys were seen to be hanging from charged parallel plates with a potential of $0 \mathrm{~V}$ and $220 \mathrm{~V}$ as shown in Figure 1. In Fig. 1 of Figure 1, a boy was hanging from a plate with a potential of $220 \mathrm{~V}$ with his both hands. On the other hand, in Fig. 2, a boy is hanging with one of his hands on the $0 \mathrm{~V}$ and the other on $220 \mathrm{~V}$ plate. Instead of their observation, which they never have, they had to base their response on their conception about voltage. Thus, only few of the students got this item correct $(18.37 \%, \chi 2=9.375, \mathrm{p}=0.001)$. From this result, it seems that first-year students still think that high voltage (whether static or alternating) is hazardous instead of the potential difference. The fact that student' responses for the two voltage items were somewhat contradictory even though the physical conditions were almost the same and worth noting.

The other three items were about properties and functions of a resistor in electric circuit. As indicated in Table 1, students' correct responses were distributed in the intermediate range. Responses of physics and chemistry students to these three first tier items taken together and marked as correct and incorrect appeared to be randomly distributed except in the fifth item for which there were only $30.6 \%(15)$ correct responses $(\chi 2=7.375, \mathrm{p}=0.007)$. Students' correct responses to item 3 and 4 were relatively higher $(44.9 \%, \chi 2=0.326, p=0.048$ and $55.1 \%, \chi 2=0.735$, $\mathrm{p}=0.475$, respectively) than that for item 5 . However, it should be recalled that students' response distributions for these items over the four and five alternative answers were found to be none randomly distributed. That means the first-year physics and chemistry students in this study made distinct choices even though those choices were mostly incorrect.

The first-year students, who had already taken the calculus based electricity and magnetism courses in which they had opportunities to mathematically solve several problems involving resistor, did still believe that either the 
Table 2. Comparison of correct response distribution for the first-tier items by department

\begin{tabular}{ccccccc} 
& \multirow{2}{*}{ Total (N) } & \multirow{2}{*}{ Total (\%) } & \multirow{2}{*}{ Chemistry (\%) } & \multirow{2}{*}{ Physics (\%) } & \multicolumn{2}{c}{ Comparison by Department } \\
\cline { 6 - 8 } Item 1 & 42 & 85.71 & 87.50 & 82.35 & 0.240 & P-Value \\
\hline Item 2 & 9 & 18.37 & 18.75 & 17.65 & 0.009 & .624 \\
\hline Item 3 & 22 & 44.90 & 50.00 & 35.29 & 0.970 & .325 \\
\hline Item 4 & 27 & 55.10 & 65.63 & 35.29 & 4.128 & .042 \\
\hline Item 5 & 15 & 30.61 & 37.50 & 17.65 & 2.060 & .151 \\
\hline
\end{tabular}

Table 3. Distribution of reasons given by students for their responses of first-tier items

\begin{tabular}{ccccccc}
\hline & A & B & C & D & $\chi^{2}$ & P-Value \\
\hline Item 1 & - & 12 & 32 & 5 & 19 & .000 \\
\hline Item 2 & 3 & 13 & 14 & -041 & 11.000 & .012 \\
\hline Item 3 & 16 & 27 & 6 & 13.510 & .001 & .003 \\
\hline Item 4 & - & 15 & 16 & 18 & .939 & 2.673 \\
\hline Item 5 & 10 & 14 & 16 & 9 & .445 \\
\hline
\end{tabular}

resistance of a resistor increases with its size $(36.7 \%)$ or size has nothing to do with the magnitude of the resistance (18.4\%). In items 4 and 5, students were given a problem in which the function of a resistor in electric circuit was asked with the resistor at different places with respect to a lamp in series circuit. In item 4, a little more than half of the first-year university students correctly answered that increasing resistance in a circuit reduces the current and consequently resulting in a decrease in the brightness of a lamp. It was observed that this response was statistically significant $(55.1 \%, \chi 2=0.735, \mathrm{p}=0.475)$, though it was marginally. Still a significant minority of the firstyear students $(32.6 \%)$ believe that there is no relationship between the brightness of the lamp and the resistor in series circuit. Students' responses to item 5 partly corroborated the finding related to item 4 and also bring about current consumption model of student conception. Similar observations were made for introductory physics students and PhD students in Li and Singh (2016) and also for high school students in the study conducted by Kock, et al., (2015).

In addition to the correct/incorrect response distribution of all students in this study, comparison was made between chemistry students who took 'Electricity and Magnetism' course and physics students who took 'Electromagnetism'. This comparison was needed to see if the difference in their entry profile had resulted in any difference in their voltage and resistance conceptions.

In general, physics majors are considered to have lower profiles at entry (Getinet, 2006; Semela, 2010) than students joining any other fields. Therefore, the data in Table 2 here seemed to be evidencing the implication of the weaker academic background of physics students when taken from the surface. However, chi-square test revealed that there was no statistically significant difference between the two groups at least regarding their response rates to the five first-tier items. The only apparent significance was in relation to item 4 which was related to the role of a resistor in series circuit. Even here, the statistically significant difference had no practical significance (Odds ratio $=0.987$ ) to imply that physics students were inferior to chemistry students in any meaningful ways.

In order to diagnose the underlying students' conceptions on which they based their responses to the first-tier items, a set of reasons were provided to them in the second-tier to each item. In Table 3, the distributions of firstyear students in this study across the alternative explanations are presented.

As can be seen in Table 3, students' choices of reasons for their answers to the first-tier questions were distinctly distributed. A fussy reasoning was given only in relation to item 5 . In the second tier of item 1, the first-year students clearly showed that they did not consider the voltage in the electric transmission cable as low voltage by rejecting the given alternative " $\mathrm{A}$ ". In addition, majority of the students $(\mathrm{N}=32,65.3 \%)$ clearly made distinction between voltage and potential difference by choosing alternative " $\mathrm{C}$ ". Alternative " $\mathrm{C}$ " which was actually the correct reason, states that "Birds do not get hurt because there is very small and negligible electric potential difference on their legs."

In item 2, where majority of the students' failed to answer the first-tier correctly ( $81.6 \%$ failure rate), their reasons were also varied. The most favored reason in this item was choice " $\mathrm{D}$ " $(\mathrm{N}=19,38.8 \%)$ which states "boys are in danger in both figures, but the danger in Fig.1 is greater because the potential difference between the hands of boy in Fig.1 is greater."

The students' reasons distribution in item 1 and 2 taken together implied that these students had lots of naïve conceptions in relation to the concepts of voltage and potential difference. Table 4 summarized the misconceptions held by first-year students even after learning through a high-level physics course in electricity and magnetism. 
Table 4. Some of students' misconceptions about voltage

\begin{tabular}{llc}
\hline Item & Conception & Mean choice \\
\hline Item 1 & No potential difference in conductors & $24.5 \%$ \\
\hline Item 1 \& 2 & High voltage is dangerous & $46.9 \%$ \\
\hline Item 2 & High voltage is dangerous when there is connecting wire & $6.1 \%$ \\
\hline Item 2 & $\begin{array}{l}\text { There is potential difference between two points even if the points are at the } \\
\text { same high voltage }\end{array}$ & $18.4 \%$ \\
\hline
\end{tabular}

Table 5. Percentage of correct responses for the second-tier items by department

\begin{tabular}{ccccccc}
\hline & \multirow{2}{*}{ Total (N) } & \multirow{2}{*}{ Total (\%) } & \multirow{2}{*}{ Chemistry (\%) } & \multirow{2}{*}{ Physics (\%) } & \multicolumn{2}{c}{ Comparison by Department } \\
\cline { 6 - 7 } & & & & & $\chi^{\mathbf{2}}$ & P-Value \\
\hline Item 1 & 32 & 65.31 & 71.88 & 52.94 & 1.757 & .185 \\
\hline Item 2 & 13 & 26.53 & 28.13 & 23.53 & 0.120 & .729 \\
\hline Item 3 & 27 & 55.10 & 62.50 & 41.18 & 2.040 & .153 \\
\hline Item 4 & 18 & 36.73 & 31.25 & 47.06 & 1.194 & .275 \\
\hline Item 5 & 14 & 28.57 & 28.13 & 29.41 & 0.009 & .924 \\
\hline
\end{tabular}

The abundance of these conceptions was as high as $46.9 \%$ and the distinct misconceptions were still existent $(6.1 \%)$ even if students had taken an advanced physics course. These conceptions are in line with what had been found from secondary students (Kock et al., 2015) as well as university introductory physics students (Li \& Singh, 2016). This means, the learning of physics at a higher level did not help these students at least to reduce their misconceptions with respect to the concept of voltage.

As presented in Table 3, first-year chemistry and physics students supported their responses to the first-tier items pertaining to the concept of resistance (item 3, 4, and 5). The reason that got most preference $(55.1 \%$, $\chi 2=13.510, p=0.001)$ by the students is the correct reason for item 3 that reads as "brightness of the lamp increases, when the resistance in the wire is smaller". However, it is important to note that only $45 \%$ of the students got the first-tier of this item right while $55 \%$ have got the right reason. This may be a sign of difficulty in applying knowledge to solve a concrete problem. Correct reasons for item 4, where the effect of resistor in a simple circuit is asked was found to be as high as $36.7 \%(\chi 2=13.939, \mathrm{p}=0.003)$. However, assertions such as that "change of the resistor only influences the brightness of the lamp if the lamp is behind the resistor" which is implicit form of the conception that resistor consumes current and that "it is the same battery in the circuit, and therefore, the same current is delivered" were also rated nearly as high as the correct reasoning. This means, students hold similar misconceptions about the functions of resistors in electric circuits and properties of voltage even after learning through advanced level course.

Except in item 5, students clearly selected non-random choices to support their responses. Item 5 kept being difficult for these students both in first-tier and second tier cases. As it is evident in literature (Bilal \& Erol, 2009; Engelhardt \& Beichner, 2004), the first-year students in the current study (N=10, 20.4\%) were still found to think that larger resistance means larger current. About the same number of students as in item $4(\mathrm{M}=16,32.6 \%)$, used their "same battery" idea to justify their response in the first-tier. Therefore, despite taking an advanced physics course in which they were solving large number of mathematical problems based on similar contexts, the first-year physics and chemistry students still have misconceptions in voltage and resistance areas.

Studies conducted in Ethiopia, as described above, suggested that Physics majors would come to the field with inferior profile compared with others (Getinet, 2006; Semela, 2010). Therefore, the participants in this study were expected to have difference in the degree of having the correct conceptions related to the tested items: voltage and resistance. To see this, comparison was also made between physics and chemistry majors in terms of the distribution of correct reasons among them (Table 5).

As seen in Table 5, the highest and lowest correct response rates for the reasons were related to item 1 and 2 , respectively. Even if as high as $85.7 \%$ students correctly answered the first-tier question in item 1 , only $65.3 \%$ could substantiate their response with the correct reasoning. In the case of item 2, more proportion of students $(26.5 \%)$ had the correct reasoning than the proportion of students who correctly answered the first-tier part. From the data in Table 5, it appears that chemistry majors scored higher in some of second-tier items (item 1, 2, and 3) and physics majors with the rest (item 4 and 5). Nevertheless, none of these differences were found to be statistically significant to warrant the expectation of lower status of physics majors than chemistry majors.

Table 6 presents the summary of some of the common misconceptions related to resistance found in this study. 
Table 6. Some misconceptions of first year students about resistance and its functions in simple electric circuits

\begin{tabular}{llc}
\hline Item & Conception & Mean choice \\
\hline Item 3 & Thicker wires have larger resistance even if the length of the wires kept constant. & $34.7 \%$ \\
\hline Item 3 and 4 & Large resistance increases the brightness of a lamp in a circuit. & $28.6 \%$ \\
\hline Item 3 & The resistances of connecting wires do not affect the brightness of a lamp in a circuit. & $16.3 \%$ \\
\hline \multirow{2}{*}{ Item 4 and 5 } & $\begin{array}{l}\text { The location of a resistor has an impact on the brightness of a lamp. Resistor on the battery } \\
\text { side consumes the current. }\end{array}$ & $26.5 \%$ \\
\hline Item 4 and 5 & The property of a circuit is determined by the battery but not by the resistance in the circuit & $31.6 \%$ \\
\hline
\end{tabular}

Table 7. Percentage of students on the different conception levels with respect to voltage and resistance concepts

\begin{tabular}{llccccc}
\hline & Department & Item 1 & Item 2 & Item 3 & Item 4 & Item 5 \\
\hline \multirow{2}{*}{ No Understanding } & Chemistry & 9.40 & 68.80 & 31.30 & 28.10 & 56.30 \\
\cline { 2 - 7 } & Physics & 17.60 & 76.50 & 47.10 & 41.20 & 64.70 \\
\cline { 2 - 7 } Specific Misconception & Total & 12.20 & 71.40 & 36.70 & 32.70 & 59.20 \\
\hline \multirow{2}{*}{ Partial Understanding } & Chemistry & 18.80 & 3.10 & 6.30 & 40.60 & 15.60 \\
\cline { 2 - 7 } & Physics & 29.40 & 0.00 & 11.80 & 11.80 & 5.90 \\
\cline { 2 - 7 } & Total & 22.40 & 2.00 & 8.20 & 30.60 & 12.20 \\
\hline \multirow{2}{*}{ Sound Understanding } & Chemistry & 3.10 & 12.50 & 18.80 & 6.30 & 6.30 \\
\cline { 2 - 7 } & Physics & 0.00 & 5.90 & 17.60 & 23.50 & 17.60 \\
\cline { 2 - 7 } & Total & 2.00 & 10.20 & 18.40 & 12.20 & 10.20 \\
\hline & Chemistry & 68.80 & 15.60 & 43.80 & 25.00 & 21.90 \\
\cline { 2 - 7 } & Physics & 52.90 & 17.60 & 23.50 & 23.50 & 11.80 \\
\cline { 2 - 7 }
\end{tabular}

The misconceptions held by the first-year students vary in abundance from $16.3 \%$ for "connecting wires have no effect in a circuit" to $34.7 \%$ for "large size means large resistance". Just like the misconceptions related to voltage, the first-year students have the same common misconceptions found elsewhere (Bilal \& Erol, 2009; Kock et al., 2015; $\mathrm{Li} \&$ Singh, 2016). This showed that misconceptions were found with high abundance after the respondents completed the introductory university physics course.

The main objective of this study was to determine the levels of conceptions about voltage and resistance of the first-year university students. In order to determine the conception levels, the coding and rating skims used by Cocstu and Ayas (2005), Ozkan and Selcuk (2015), and Tarakçı et al. (1999) was used. According to this categorization, based on students' responses in the first and second-tier conceptual test items were labeled as "Sound understanding" with 3 points weight, "Partial understanding" with 2 points, "Specific misconception" with 1 , and "No understanding" with the least 0 weight. The percentage distribution of first-year students over the different levels are presented in Table 7.

In general, the first-year students populated much of the lower end of the scale (No Understanding) and to some extent, the Sound understanding end as well. Relatively large proportion of the first-year students (63.3\%) showed sound understanding of the concept of voltage in a rather familiar realistic condition. But, the same could not be demonstrated for the same concept in the case of the same but none familiar condition - the hanging of boys from a high voltage transmission cable. In fact, the larger proportion of "No Understanding" (71.4\%) was observed in this case. On the other hand, only $36.7 \%$ of the first-year students demonstrated that they have "Sound understanding" of the property of resistance. However, $63.3 \%$ of these students were found to have one or the other problem in relation to the concept of resistance, with $36.7 \%$ of them still within the "No understanding" level. When it comes to the functioning of a resistor in a simple circuit, only $24.5 \%$ of these students showed that they have clearer understanding. Hence, it can be observed that the understanding level reached by the first-year students were still the same as that of secondary school students elsewhere (Bilal \& Erol, 2009; Kock et al., 2015).

From the data in Table 7, it can also be observed that there is difference between chemistry and physics majors with a mean deviation of $12.13 \%$. Mostly chemistry students seemed to highly populate the higher levels than the lower levels. Nevertheless, in order to see if these students do really have difference in their conception levels, their mean scores according to the weighting for different levels was calculated and compared. Independent sample ttest was used to compare the conception level means of the chemistry and physics students as presented in Table 8. 
Table 8. Comparison of mean score of students with respect to the level of conception by department

\begin{tabular}{lccccccc}
\hline Department & N & Mean (M) & Std. Deviation (SD) & Std. Error Mean & df & t & p-value \\
\hline Chemistry & 32 & 7.031 & 3.0742 & .5434 & 47 & 1.343 & .186 \\
\hline Physics & 17 & 5.765 & 3.2697 & .7930 & & & \\
\hline Equa
\end{tabular}

Equal variances assumed: Levene's Test $(F=0.411, P>0.05)$

Even though the chemistry students mean score $(M=7.03, S D=3.074)$ appeared to be higher than that of the physics majors $(\mathrm{M}=5.76, \mathrm{SD}=3.270)$, the $\mathrm{t}$-test revealed that the observed difference was not statistically significant $(\mathrm{t}=1.34, \mathrm{p}=0.186)$. This result is again surprising as the lower profile physics students during entry to the program should have been expected to perform lower than the better entry profile chemistry students. The very low mean scores (the maximum possible was 15 points) of both the chemistry and physics major imply that university students still have as many misconceptions as secondary school students even after passing through the traditional but high-level physics course.

\section{DISCUSSION AND CONCLUSION}

Now a day's physics education and science education in general is assumed to have conceptual learning as an important goal of instruction (Kock et al., 2015; Treagust \& Duit, 2009). In this research, we wanted to determine the level of conceptual understanding reached by first year university student after studying two units involving the concepts of electric potential (voltage) and resistance. The first-year students' conceptions about these concepts were investigated using a two-tier test and assigning their responses into different conception categories and different conception levels using the skim commonly used in misconception studies (for example in Ozkan \& Selcuk, 2015). After identification of first year students' conceptions, comparison with those found in literature at secondary school (Urban-Woldron, 2013; Vatansever, 2006) and university (Li \& Singh, 2016; Ozkan \& Selcuk, 2015) levels were made.

The most important students conceptions identified in this study were (a) although there are clear distinctions between the concepts of potential and potential difference, still high voltage not potential difference is hazardous; (b) there is no potential difference between points within a conductor although there is a potential difference between the points even when the conductor is maintained at the same high voltage; (c) thicker wires are more resistant than thinner ones; (d) larger resistance means larger current; (e) resistance of connecting cables have no effect on a circuit behavior; (f) the location of a resistor in a circuit determines its effect; a resistor on the battery side consumes the current to a lamp; and (g) the current in a circuit is determined by the battery not by the resistance.

Comparison of these misconceptions with those found in relevant literature revealed that the same old conceptions (Bilal \& Erol, 2009; Engelhardt \& Beichner, 2004; Kim \& Pak, 2002) were still abundant among them even after taking the university introductory physics course. For example, the conceptions about voltage found here were the same as those in Vatansever (2006) among secondary school students. Most of the other students' misconceptions found in this study were also similar to what Tsai (2003) found from grade 8 students and which were resistant to change with traditional instruction. Some degree of resemblances for some of the misconceptions found in this study was also found with those studies in universities elsewhere (Engelhardt \& Beichner, 2004; Li \& Singh, 2016).

In their review of the literature relevant to this area, Kock et al. (2015) summarized students' misconceptions related to the concepts of voltage and resistance in simple circuits. In this study, the Kock et al. list was found to be confirmed by the above list we found among first year physics and chemistry students after learning two units at a higher level. This result suggests that even if students learn physics at a university level with a higher-level curriculum, the conception students formed at school level about voltage and resistance concepts were not affected. This is of course not only with first year university students; even PhD students in physics do share the misconceptions to some extents ( $\mathrm{Li} \&$ Singh, 2016). This is an indication of failure of the content driven curriculum which was developed based on the abstract logic of the subject matter instead of taking into account students' ideas and learning difficulties. Instead of targeting conceptual learning of such basic concepts as voltage and resistance, it university physics courses speed up the mathematical representations and abstract manipulations of the concepts. Under such conditions, the students' misconceptions are overlooked during instruction and remain to limit their understanding and further progress in their learning (Kock et al., 2013).

Treagust and Duit (2009) acknowledged that science teaching at every level of education should aim at creating conditions for students to conceptually learn the content. If conceptual change and conceptual learning are desired, attention must be given to the ideas and problems students bring to the classroom. To this end, the classroom culture where students are treated as passive recipients of the high-level content knowledge mediated by the teachers talk should be replaced by the one including the social processes of knowledge building and the epistemic side of the curriculum (Kock et al., 2013; Duschl, 2008). 
The other related finding in this study was the fact that the first-year students had contradictory views about the same concept: concept of voltage. When they were given a voltage problem in a very familiar situation (birds on high voltage cable) majority of them did not say high voltage is dangerous in any conditions. Nevertheless, when the same problem was presented to them in an unlikely and unfamiliar case of a boy hanging from a plate maintained at a high voltage, most of them depended on their "high voltage is hazardous" conception. This fact is at odds with the classical conceptual change model of Posner and his colleagues (Treagust \& Duit, 2009) which assert that students have a single conception that changes revolutionarily whenever an intelligible, plausible, and fruitful conception is available. Instead, this seems to evidence the second perspective of knowledge which asserts that students' knowledge is more like conceptual ecology of quasi-independent elements (Ozdemir \& Clark, 2007). If conceptual change were to occur according to the classical epistemological recommendation, such contradictory ideas would not have co-existed. According to this view, when students are confronted with contradictory conditions with their existing ideas, dissatisfaction which leads to the revolutionary replacement of the previous idea would occur. However, the finding in this study revealed that even contradictory ideas do co-exist instead of one replacing the other. But, as Ozdemir and Clark (2007), Treagust and Duit (2009) argued that conceptual change instruction should not be guided based on a single perspective. They recommended that research and instruction in conceptual change should at least include the classical- epistemological, ontological and affective orientations.

In this research, the first-year students' conception levels were determined using a scale with a maximum point 3 (sound understanding) to a minimum of 0 (no understanding) as in Ozkan and Selcuk (2015). A low mean score of about 6.59 out of 15 maximum point was obtained which could be translated to a score of 2.2 points on the above scale and which means the average level of understanding reached was far from "sound understanding". Hence, we conclude that the average conception level reached by the first-year students after learning two units on the concepts of the test was "partial understanding". It can be observed that the understanding level reached by the first-year students were still the same as that of secondary school students elsewhere (Bilal \& Erol, 2009; Kock et al., 2015). This result confirmed the finding of Duit and Treagust (2003) which implied that attending advanced but traditional university physics course would not help students to improve their physics understanding. Başer and Geban (2007) also showed that misconceptions held by students before and after traditional physics instruction were the same. Hence, one cannot escape here from concluding that the traditional but high-level physics course would not help in conceptual physics learning. This is in consonance with the findings obtained in literature (Bilal \& Erol, 2009; Duschl, 2008; Li \& Singh, 2016).

Despite the presumed academic background differences between the chemistry and physics majors, no statistically significant difference in their conception levels were obtained. As no progress was observed between school and university studies, in this research, we cannot attribute this lack of differentiation among the first-year students to the normalizing effect of instruction. What was found in this study was that university students still had as many misconceptions as secondary school students even after passing through the traditional but high-level physics course. This is in line with the findings obtained in literature (Duit \& Treagust, 2003; Li \& Singh, 2016; Ozkan \& Selcuk, 2015). Therefore, instead of normalizing the difference among first year students', we found that the high level physics course did not result in better students' conceptual understanding. Since such courses were commonly taught using the traditional methods, teachers were not utilizing well tested conceptual change teaching methodologies such as those discussed in the science conceptual change literature as Ozkan and Selcuk (2012) and Treagust and Duit (2009). As a result, we conclude that physics teachers' do not give due attention to students' ideas and misconceptions in their traditional direct teaching lessons. Hence, instead of attaching student's failure to their poor entry background, instructors have to look for an opportunity to expose the less able students to a variety of conceptual change teaching strategies which help them learn and understand the basic concepts of the topics being taught.

\section{ACKNOWLEDGEMENT}

The researchers thank the instructors and students of Medda Walabu University who participated in the study.

\section{REFERENCES}

Adula, B., \& Kasahun, M. (2010). Enactment of Student-Centered Approach in Teaching Mathematics and Natural Science: The Case of Selected General Secondary Schools in Jimma Zone, Ethiopia. Ethiopian Journal of Education and Sciences, 5(2), 29-50. https://doi.org/10.4314/ejesc.v5i2.65367

Başer, M., \& Geban, Ö. (2007). Effect of instruction based on conceptual change activities on students' understanding of static electricity concepts. Research in Science E Technological Education, 25(2), 243-267. https:/ / doi.org/10.1080/02635140701250857 
Bekalo, S. A., \& Welford, A. G. (1999). Secondary pre-service teacher education in Ethiopia: its impact on teachers' competence and confidence to teach practical work in science. International Journal of Science Education, 21(12), 1293-1310. https:/ / doi.org/10.1080/095006999290084

Bilal, E., \& Erol, M. (2009). Investigating students' alternative conceptions of some electricity concepts. Latin American Journal of Physics Education, 3(2), 193 - 201.

Chee, C. T. (1996). Common misconceptions in frictional force among university physics students. Teaching and Learning, 16(2), 107-116.

Cocstu, B., \& Ayas, A. (2005). Evaporation in different liquids: secondary students' conceptions. Research in Science E Technological Education, 23(1), 75-97. https:/ / doi.org/10.1080/02635140500068476

Dalaklioğlu, S., Demirci, N., \& Şekercioğlu, A. (2015). Eleventh Grade Students' Difficulties and Misconceptions about Energy and Momentum Concepts. International Journal on New Trends in Education and Their Implications, 6(1), 13 - 21.

Dilber, R., Karaman, I., \& Duzgun, B. (2009). High school students' understanding of projectile motion concepts. Educational Research and Evaluation, 15(3), 203-222. https:/ / doi.org/10.1080/13803610902899101

Driver, R. (1989). Students' conceptions and the learning of science. International Journal of Science Education, 11, 481 - 490. https:/ / doi.org/10.1080/0950069890110501

Duit, R., \& Treagust, D. F. (2003). Conceptual change: a powerful framework for improving science teaching and learning. International Journal of Science education, 25(6), 671 - 688. https:/ / doi.org/10.1080/09500690305016

Duit, R., Treagust, D. F., \& Mansifield, H. (1996). Investigating students' understanding as a prerequisite to improving teaching and learning in science and mathematics. In D. F. Treagust, R. Duit \& B. J. Fraser (eds.), Improving teaching and learning in science and mathematics (pp. 1-14). New York: Teachers College Press.

Duschl, R. (2008). Science Education in Three-Part Harmony: Balancing Conceptual, Epistemic and Social Learning Goals. Review of Research in Education, 32, 268-291. https:/ / doi.org/10.3102/0091732X07309371

Engelhardt, P. V., \& Beichner, R. J. (2004). Students' Understanding of Direct Current Resistive Electrical Circuits. American Journal of Physics, 72(1), 98-115. https:/ / doi.org/10.1119/1.1614813

Esayas, B. (1995). A look at problems of science Education in secondary schools. In IER (eds.), Proceedings of the National Work shop on strengthening Educational Research (pp. 110-115). Addis Ababa: Institute for Educational Research, Addis Ababa University.

Federal Ministry of Education. (2015). Education Sector Development Program V (ESDP V):2008 - 2012 E.C. (2015/16 - 2019/20 G.C). Federal Ministry of Education, Addis Ababa, Ethiopia.

Getinet, T. (2006). Causes of High Attrition among Physics PPC Students of Dilla College. The Ethiopian Journal of Education, 26, 53-66.

Getinet, T. (2007). Students understanding of the basic concepts of Newtonian mechanics vis-a-vis lecture method. The Ethiopian Journal of Higher Education, 4, 23-35.

Getinet, T. (2012). Effect of instructional interventions on students learning gains: An experimental research. Lat. Am. J. Phys. Educ., 6(2), 187-195.

Gurel, D. K., Eryılmaz, A., \& McDermott, L. C. (2015). A Review and Comparison of Diagnostic Instruments to Identify Students' Misconceptions in Science. Eurasia Journal of Mathematics, Science E Technology Education, 11(5), 989-1008. https:/ / doi.org/10.12973/eurasia.2015.1369a

Hake, R. R. (1998). Interactive-engagement versus traditional methods: A six-thousand-student survey of mechanics test data for introductory physics courses. American Journal of Physics, 66(1), 64-74. https://doi.org/10.1119/1.18809

Kaltakçı, D., \& Eryilmaz, A. (2010). Identifying Pre-service Physics Teachers' Misconceptions with Three-Tier Test. In W. Kaminski \& M. Michelini (eds.), Proceedings of selected papers of the GIREP - ICPE-MPTL International conference. Reims, France.

Kim, E., \& Pak, S. (2002). Students do not Overcome Conceptual Difficulties after Solving 1000 Traditional Problems. American Journal of Physics, 70(7), 759-765. https:/ / doi.org/10.1119/1.1484151

Kock, Z., Taconis, R., Bolhuis, S., \& Gravemeijer, K., (2015). Creating a Culture of Inquiry in the Classroom While Fostering an Understanding of Theoretical Concepts in Direct Current Electric Circuits: A Balanced Approach. International Journal of Science and Mathematics Education, 13(1), 45-69. https:/ / doi.org/10.1007/s10763-014-9535-Z

Kock, Z. J., Taconis, R. Bolhuis, S., \& Gravemeijer, K. (2013). Some Key Issues in Creating Inquiry-Based Instructional Practices that Aim at the Understanding of Simple Electric Circuits. Research in Science Education, 43, 579-597. https://doi.org/10.1007/s11165-011-9278-6 
Li, J., \& Singh, C. (2016). Students' Common Difficulties and Approaches While Solving Conceptual Problems with Non identical Light Bulbs in Series and Parallel. European Journal of Physics, 37, 1-15. https://doi.org/10.1088/0143-0807/37/6/065708065708

Martin, R., Sexton, C., \& Gerlovich, J. (2002) Teaching Science for all Children: Methods for Constructing Understanding. Boston: Allyn and Bacon.

Mekonnen, S. (2014). Problems Challenging the Academic Performance of Physics Students in Higher Governmental Institutions in the Case of Arbaminch, Wolayita Sodo, Hawassa and Dilla Universities. Natural Science, 6, 362-375. https:/ / doi.org/10.4236/ns.2014.65037

Osborne, R. (1985). Children's own concepts. In W. Harlen (ed.), Primary Science: Taking the Plunge. London: Heinemann.

Ozdemir, G., \& Clark, D. B. (2007). An Overview of Conceptual Change Theories. Eurasia Journal of Mathematics, Science E Technology Education, 3(4), 351-361.

Ozkan, G., \& Selcuk, G., (2015). The Effectiveness of Conceptual Change Texts and Context-Based Learning on Students' Conceptual Achievement. Journal of Baltic Science Education, 14(6), 753-763.

Özkan, G., \& Selçuk, G. (2012). How effective is “Conceptual Change Approach" in Teaching Physics? Journal of Educational and Instructional Studies in the World, 2(2), 182-190.

Ross, K., Lakin, L., \& Callaghan, P. (2000). Teaching secondary science. London: David Fulton Publishers.

Semela, T. (2010). Who is joining physics and why? Factors influencing the choice of physics among Ethiopian University Students. International Journal of Environmental \& Science Education, 5(3), 319-340.

Serway, R. A., \& Jewett, J. W. (2008). Physics for Scientists and Engineers, With Modern Physics (7th Edition). Belmont, CA: Thomson-Brooks/Cole.

Shibeshi, A., Mekonnen, D., Semela, T., \& Endawoke, Y. (2009). Assessment of science education quality indicators in Addis Ababa, Bahir Dar, and Hawassa Universities. In A. Taye (Ed.), Quality of Higher Education in Ethiopian Public Higher Education Institutions (pp. 161-263). Addis Ababa: Forum for Social Studies.

Singh, A. (2014). Emergence and Evolution of Learning Gaps across Countries: Panel Evidence from Ethiopia, India, Peru and Vietnam, Working Paper 124. Oxford, UK: Young Lives.

Staver, J. R. (2007). Teaching science. Geneva: Educational Practices Series, The International Academy of Education (IAE) and the International Bureau of Education (UNESCO).

Taasoobshirazi, G., \& Carr, M. (2008). A review and critique of context-based physics instruction and assessment. Educational Research Review, 3(2), 155-167. https:/ / doi.org/10.1016/j.edurev.2008.01.002

Taconis, R., \& Kessels, U. (2009). How choosing science depends on students' individual fit to 'Science Culture'. International Journal of Science Education, 31(8), 1115-1132. https:/ / doi.org/10.1080/09500690802050876

Tanel, Z., \& Erol, M. (2008). Students' Difficulties in Understanding the Concepts of Magnetic Field Strength, Magnetic Flux Density and Magnetization. Lat. Am. J. Phys. Educ., 2, 184 -191.

Tarakçı, M., Hatipoğlu, S., Tekkaya, C., \& Özden, M. Y. (1999). A Cross-Age Study of High School Students' Understanding of Diffusion and Osmosis. Hacettepe Üniversitesi Eğitim Fakültesi Dergisi, 15, 84-93.

Treagust, D. (1986). Evaluating students' misconceptions by means of diagnostic multiple choice items. Research in Science Education, 16, 199-207. https:/ / doi.org/10.1007/BF02356835

Treagust, D., \& Duit, R. (2009). Multiple Perspectives of Conceptual Change in Science and the Challenges Ahead. Journal of Science and Mathematics Education in Southeast Asia, 32(2), 89-104.

Treagust, D. F., \& Haslam, F. (1986). Evaluating secondary students' misconceptions of photosynthesis and respiration in plants using a two-tier diagnostic instrument. Paper presented at the 59th annual meeting of the National Association for research in Science Teaching, San Francisco, California, March 28 - 31.

Tsai, C.-C. (2003). Using a conflict map as an instructional tool to change student alternative conceptions in simple series electric-circuits. International Journal of Science Education, 25(3), 307-327. https:/ / doi.org/10.1080/09500690210145756

Urban-Woldron, H. (2013). Testing student conceptual understanding of electric circuits as a system. In C. P. Constantinou, N. Papadouris, \& A. Hadjigeorgiou (Eds.), Proceedings of ESERA 2023, Strand 11 - Evaluation and assessment of student learning and development (pp.101-111). Retrieved from https://www.esera.org/media/eBook_2013/strand\&2011/ESERA_Proceedings

Vatansever, O. (2006). Effectiveness of Conceptual Change Instruction on Overcoming Students' Misconceptions of Electric Field, Electric Potential and Electric Potential Energy at Tenth Grade Level (Unpublished MSc thesis), Middle East Technical University. 
Walker, J., Resnick, R., \& Halliday, D. (2014). Fundamentals of Physics (Tenth edition.). Hoboken, NJ: John Wiley \& Sons, Inc.

Wang, J. (2004). Development and validation of a two-tier instrument to examine understanding of internal transport in plants and the human circulatory system. International Journal of Science and Mathematics Education, 2(2), 131 - 157. https:// doi.org/10.1007/s10763-004-9323-2

Woldeghebriel, H., \& Tenaw, T. (2013). National Modular Curriculum for the Degree of Bachelor of Science (B.Sc) in Physics. Federal Ministry of Education, Addis Ababa, Ethiopia.

\section{http://www.ejmste.com}

